\title{
Nottingham prognostic index plus (NPI+) predicts risk of distant metastases in primary breast cancer
}

\author{
Andrew R. Green ${ }^{1}$ - D. Soria ${ }^{2}$ - D. G. Powe ${ }^{3}$ C. C. Nolan ${ }^{1}$ M. Aleskandarany ${ }^{1}$ \\ M. A. Szász ${ }^{4}$ - A. M. Tökés ${ }^{4}$ G. R. Ball ${ }^{5}$ J. M. Garibaldi ${ }^{2}$ E. A. Rakha ${ }^{1,3}$. \\ J. Kulka ${ }^{4}$ I. O. Ellis ${ }^{1,3}$
}

Received: 10 February 2016/ Accepted: 19 April 2016/Published online: 26 April 2016

(c) The Author(s) 2016. This article is published with open access at Springerlink.com

\begin{abstract}
The Nottingham prognostic index plus (NPI+) is based on the assessment of biological class combined with established clinicopathologic prognostic variables providing improved patient outcome stratification for breast cancer superior to the traditional NPI. This study aimed to determine prognostic capability of the NPI+ in predicting risk of development of distant disease. A well-characterised series of 1073 primary early-stage BC cases treated in Nottingham and 251 cases from Budapest were immunohistochemically assessed for cytokeratin $(\mathrm{Ck}) 5 / 6$, Ck18, EGFR, oestrogen receptor (ER), progesterone receptor, HER2, HER3, HER4, Mucin 1 and p53 expression. NPI+ biological class and prognostic scores were assigned using individual algorithms for each biological class incorporating clinicopathologic parameters and investigated in terms of prediction of distant metastases-
\end{abstract}

Electronic supplementary material The online version of this article (doi:10.1007/s10549-016-3804-1) contains supplementary material, which is available to authorized users.

Andrew R. Green

andrew.green@nottingham.ac.uk

1 Division of Cancer and Stem Cells, School of Medicine, Breast Cancer Pathology Research Group, Academic Unit of Oncology, Nottingham City Hospital, University of Nottingham, Hucknall Road, Nottingham NG5 1PB, UK

2 Computer Science and Advanced Data Analysis Centre, University of Nottingham, Nottingham, UK

3 Cellular Pathology, Nottingham University Hospitals NHS Trust, Nottingham, UK

4 Second Department of Pathology, Semmelweis University, Budapest, Hungary

5 School of Science and Technology, College of Arts and Science, Nottingham Trent University, Nottingham, UK free survival (MFS). The NPI+ identified distinct prognostic groups (PG) within each molecular class which were predictive of MFS providing improved patient outcome stratification superior to the traditional NPI. NPI+ PGs, between series, were comparable in predicting patient outcome between series in luminal A, basal p53 altered and HER $2+/ E R+(p>0.01)$ tumours. The low-risk groups were similarly validated in luminal B, luminal $\mathrm{N}$, basal p53 normal tumours $(p>0.01)$. Due to small patient numbers the remaining PGs could not be validated. NPI+ was additionally able to predict a higher risk of metastases at certain distant sites. This study may indicate the NPI+ as a useful tool in predicting the risk of metastases. The NPI+ provides accurate risk stratification allowing improved individualised clinical decision making for breast cancer.

Keywords Breast cancer - Classification - Prognostic index $\cdot$ Molecular $\cdot$ Clinical $\cdot$ Outcome

\section{Introduction}

Breast cancer (BC) is remarkably heterogeneous with respect to genotypic, phenotypic and behavioural characteristics and subsequent response to treatment. With an increasing number of treatment options available for BC patients, deciding the most appropriate choice remains challenging. However, accurate personalised BC treatment requires robust and accurate risk stratification based on both outcome prediction and biology of tumours [1], combined with therapeutic modality response and resistance assessment.

The Nottingham prognostic index (NPI) [2-5] is based on histopathological factors (tumour size, lymph node stage and tumour grade) and is used to stratify BC patients 
with operable early-stage primary $\mathrm{BC}$ into prognostic groups. The NPI accuracy has been confirmed using longterm patient follow-up [2], validated in large independent multi-centre studies $[3,6]$, revised in order to stratify patients into additional prognostic groups [7], and is currently adopted in clinical practice in the UK and other parts of Europe and Australia. However, the NPI does not consider the biological heterogeneity of $\mathrm{BC}$ and it therefore needs further refinement to support a more sophisticated personalised management of patients.

We have therefore developed a biomarker-based prognostic index, Nottingham prognostic index plus (NPI+) [8], using a large well-characterised series of early-stage BC. NPI+ is based on the well-established clinicopathologic variables used in the NPI but has been refined to integrate with tumour biology. It utilises routine formalin-fixed clinical samples and immunohistochemistry (IHC) thus providing an easy adoption into the current international clinical practice. NPI+ is based on a two-tier evaluation; initially the biological class of the tumour is determined and is then combined with clinicopathologic prognostic variables resulting in bespoke NPI-like formulae for each biological class [8-11]. NPI+ is able to assist in predicting long-term patient survival and to support clinical decision making in BC management [8]. Breast tumours are classified into seven core $\mathrm{BC}$ biological classes by the evaluation and combination of 10 BC-related biomarkers using IHC [12]. The molecular classes identified are three luminal classes (Luminal A, N and B), two basal classes (Basal-p53 altered and Basal-p53 normal) and two HER2+ classes (HER2+/ $\mathrm{ER}+$ and HER2+/ER-). Each biological class is further stratified using a set of well-defined prognostic clinicopathologic variables which are combined in tailored formulae to stratify each individual molecular class into several prognostic subgroups (NPI+ Groups) which are superior to the classic NPI [8]. Recently, we have further refined the NPI+ algorithms and validated the NPI+ in an independent series of primary BC confirming its reproducibility in providing accurate risk stratification allowing improved individualised clinical decision making for $\mathrm{BC}$ [13].

In this study, we aimed to determine the applicability of NPI+ to predict risk of distant metastases in two series of clinically annotated early-stage primary invasive BC.

\section{Patients and laboratory methods}

\section{Nottingham series}

A series of 1073 patients from the Nottingham-Tenovus Primary Breast Carcinoma Series, aged 70 years or less, presenting with primary operable (stages I, II and IIIa) invasive BC between 1986 and 1998 were previously used to develop the NPI+ [8-11]. This is a well-characterised consecutive series of patients who were uniformly treated according to locally agreed clinical protocols (Abd ElRehim et al. [9]). All tumours were less than $5 \mathrm{~cm}$ diameter on clinical/pre-operative measurement and/or on operative histology (T1 and T2). Women aged over 70 years were not included because of the increased confounding effect of comorbidities/death from other causes and because the primary treatment protocols for elderly patients often differed from those for younger women. Adjuvant systemic therapies were offered according to the Nottingham prognostic index (NPI) and hormone receptor (HR) status [2, 7]. Patients in the Moderate I group (NPI 3.41-4.4) with HRpositive tumours were offered hormonal therapy. Patients in the Moderate II (NPI 4.41-5.4) and Poor (NPI > 5.41) groups received hormone therapy for HR-positive tumours and cytotoxic therapy (classical cyclophosphamide, methotrexate and 5-fluorouracil (CMF)) for HR-negative tumours and if the patient was fit enough to tolerate chemotherapy. Hormonal therapy was given to 396 patients (40.3\%), chemotherapy to $213(19.9 \%)$. Only 19 patients $(1.9 \%)$ received a combination of chemotherapy and endocrine therapy (Table 1). Data relating to survival were collated in a prospective manner for those patients presenting after 1989 only. All samples from Nottingham used in this study were pseudo-anonymised and collected prior to 2006 and therefore under the Human Tissue Act informed patient consent was not needed. Release of data was also pseudo-anonymised as per Human Tissue Act regulations.

\section{Budapest series}

This series comprised 368 screen detected and symptomatic consecutive cases diagnosed with primary breast cancer between 1999 and 2002 and operated at the Buda MÁV hospital, Budapest, Hungary. A total of 251 cases were assembled in TMAs; the remaining cases were not included due to technical reasons or lack of relevant data. The age range of patients was 30-88 years, and pathological size was $14 \mathrm{~cm}$ and less. All pT stages and inflammatory breast cancers were included. A total of $42.4 \%$ of the patients received the classical Bonadonna scheme (CMF), at the time the standard chemotherapy, unless comorbidities or advanced age permitted. Patients with hormone receptor positive invasive tumours were treated with Tamoxifen. According to the radiation therapy recommendations valid at the time, loco-regional radiation therapy was added to the postoperative treatment in cases of breast conservation and in those patients undergoing mastectomy who had 4 or more axillary lymph node metastases (134 patients, $57.4 \%$ ). Pathological features 
Table 1 Pathological characteristics of the Nottingham and Budapest series

\begin{tabular}{|c|c|c|c|}
\hline & $\begin{array}{l}\text { Nottingham } \\
n(\%)\end{array}$ & $\begin{array}{l}\text { Budapest } \\
n(\%)\end{array}$ & $p$ value \\
\hline \multicolumn{4}{|l|}{ Grade } \\
\hline 1 & $158(14.7)$ & $102(40.8)$ & \\
\hline 2 & $348(32.4)$ & $72(28.8)$ & \multirow[t]{2}{*}{$<0.001$} \\
\hline 3 & $567(52.8)$ & $76(30.4)$ & \\
\hline \multicolumn{4}{|c|}{ Tubule formation } \\
\hline 1 & $53(5.0)$ & $36(15.1)$ & \multirow{3}{*}{$<0.001$} \\
\hline 2 & $346(33.0)$ & $57(23.8)$ & \\
\hline 3 & $651(62.0)$ & $146(61.1)$ & \\
\hline \multicolumn{4}{|l|}{ Pleomorphism } \\
\hline 1 & $19(1.8)$ & $57(23.4)$ & \multirow{3}{*}{$<0.001$} \\
\hline 2 & $378(36.1)$ & $93(38.1)$ & \\
\hline 3 & $651(62.1)$ & $94(38.5)$ & \\
\hline \multicolumn{4}{|l|}{ Mitosis } \\
\hline 1 & 349 (33.2) & $114(47.5)$ & \multirow{3}{*}{$<0.001$} \\
\hline 2 & $190(18.1)$ & $73(30.4)$ & \\
\hline 3 & $511(47.6)$ & $53(22.1)$ & \\
\hline Size & $\begin{array}{l}0.13-10 \mathrm{~cm} \\
(\text { median } \\
2.0 \mathrm{~cm})\end{array}$ & $\begin{array}{c}0.3-14 \mathrm{~cm} \\
(\text { median } \\
2.1 \mathrm{~cm})\end{array}$ & \\
\hline$<1.5 \mathrm{~cm}$ & $240(22.4)$ & $68(27.1)$ & 0.111 \\
\hline$\geq 1.5 \mathrm{~cm}$ & 833 (77.6) & $183(72.9)$ & \\
\hline \multicolumn{4}{|l|}{ Stage } \\
\hline 1 & $654(61.0)$ & $88(48.1)$ & \multirow{3}{*}{$<0.001$} \\
\hline 2 & $330(30.8)$ & $55(30.1)$ & \\
\hline 3 & $88(8.2)$ & $40(21.9)$ & \\
\hline \multicolumn{4}{|c|}{ Lymph nodes positive } \\
\hline 0 & $608(48.9)$ & $90(48.9)$ & \multirow{4}{*}{$<0.001$} \\
\hline $1-3$ & 318 (31.6) & $55(29.9)$ & \\
\hline $4-9$ & $70(7.0)$ & $29(15.8)$ & \\
\hline$>9$ & $11(1.1)$ & $10(5.4)$ & \\
\hline \multicolumn{4}{|c|}{ Nottingham prognostic index } \\
\hline Excellent & $110(10.3)$ & $27(14.8)$ & \multirow{6}{*}{0.008} \\
\hline Good & 200 (18.6) & $31(17.0)$ & \\
\hline Moderate 1 & $293(27.3)$ & $45(24.7)$ & \\
\hline Moderate 2 & $277(25.8)$ & $39(21.4)$ & \\
\hline Poor & $140(13.0)$ & $20(11.0)$ & \\
\hline Very poor & $45(4.2)$ & $20(11.0)$ & \\
\hline \multicolumn{4}{|l|}{ Chemotherapy } \\
\hline No & $807(75.2)$ & $141(57.6)$ & \\
\hline Yes & $213(19.9)$ & $104(42.4)$ & $<0.001$ \\
\hline \multicolumn{4}{|l|}{ Metastases } \\
\hline Yes & $363(33.9)$ & $49(21.1)$ & \multirow[t]{2}{*}{$<0.001$} \\
\hline No & $707(66.1)$ & $183(78.5)$ & \\
\hline \multicolumn{4}{|c|}{ Site of metastases } \\
\hline Bone & $219(20.5)$ & - & \\
\hline Brain & $57(5.3)$ & - & \\
\hline Liver & 149 (13.9) & - & \\
\hline
\end{tabular}

Table 1 continued

\begin{tabular}{llll}
\hline & $\begin{array}{l}\text { Nottingham } \\
n(\%)\end{array}$ & $\begin{array}{l}\text { Budapest } \\
n(\%)\end{array}$ & $p$ value \\
\hline Lung & $91(8.5)$ & - \\
Lymph node & $50(4.7)$ & - \\
Pleura & $35(3.3)$ & - \\
Visceral & $24(2.3)$ & - \\
Other & $51(4.8)$ & - \\
Metastases-free & $0-243$ & $0-123$ \\
survival (months) & (median 119) & (median 96) \\
\hline
\end{tabular}

were retrieved from the pathology reports and slides were reviewed. Treatment data were collected from patients' medical records. The evaluation was approved by the Institutional Review Board of Semmelweis University (IKEB, \#185/2007). No informed consent was required by the Institutional Ethical Committee.

Pathological characteristics of both series are summarised in Table 1. Metastases-free survival (MFS) is defined as the interval (in months) between the primary surgery and occurrence of metastases being scored as an event. Metastases did not include local (ipsilateral) or regional recurrences, contralateral breast cancer. Lymph node metastases did not include regional lymph nodes. Patients who did not have metastatic disease were censored at the time of last follow-up.

This study was approved by the Nottingham Research Ethics Committee 2 under the title 'Development of a molecular genetic classification of breast cancer'.

\section{Determination of NPI+ biological class}

Immunohistochemical reactivity for the NPI+ biomarkers in the Nottingham series was previously determined using standard immunocytochemical techniques on tumour samples prepared as tissue microarrays (TMAs) [9]. The NPI+ biomarkers used for classification were oestrogen receptor (ER), progesterone receptor (PgR), cytokeratin (CK) 5/6, CK7/8, epidermal growth factor receptor (EGFR; HER1), c-erbB2 (HER2), c-erbB3 (HER3), c-erbB4 (HER4), p53, and Mucin 1 [11]. TMAs of the Budapest series were additionally stained for the NPI+ biomarkers using the same procedures as previously described $[9,11]$. The Budapest TMAs consisted of $2 \mathrm{~mm}$ tissue cores and were produced as previously described [14]. Each tumour was represented by two cores. Levels of immunohistochemical reactivity were determined by microscopic assessment using the modified Histochemical score $(H$ score), giving a semi-quantitative assessment of both the intensity of staining and the percentage of positive cells (values between 0 and 300) [15, 16]. For HER2, the American Society of Clinical Oncology/College of American Pathologists Guidelines Recommendations for HER2 Testing in 
Breast Cancer were used for assessment [17]. Equivocal $(2+)$ HER2 + cases were confirmed by FISH/CISH [18]. The Reporting Recommendations for Tumour Marker Prognostic Studies (REMARK) criteria [19] were followed.

\section{Determination of NPI+ score}

For biological classification, a fuzzy logic rule-based method algorithm was used where the cut-offs for each biomarker were previously determined [12]. In particular, the median value of markers was used for ER, PgR, CK7/8, HER3, HER4 and MUC1. The expertise values were used for those markers which had a median equal to zero and for those where clinicians were sure about the value to consider (CK5/6, EGFR, p53 and HER2).

The NPI+ prognostic groups were calculated using bespoke NPI-like formulae, previously developed for each NPI+ biological class of the Nottingham series, utilising the existing available clinicopathological parameters [8]. Briefly, these were established by utilisation of the Beta values generated by Cox regression analysis in predicting breast cancer-specific survival of the well-established histopathologic prognostic factors. These formulae were initially derived from the Biological Classes in Green et al. [11] and were subsequently refined using the improved biological classification used in Soria et al. [12] consisting of number of positive nodes, pathological tumour size,
Table 2 Distribution of NPI+ biological classes within the Nottingham and Budapest Series

\begin{tabular}{llll}
\hline NPI+ class & Nottingham $(n=1035) n(\%)$ & Budapest $(n=266) n(\%)$ & $p$ value \\
\hline Luminal A & $288(27.8)$ & $84(31.6)$ & 0.005 \\
Luminal N & $205(19.8)$ & $32(12.0)$ & \\
Luminal B & $186(18.0)$ & $65(24.4)$ & \\
Basal p53 altered & $113(10.9)$ & $18(6.8)$ & \\
Basal p53 normal & $96(9.3)$ & $36(13.5)$ & \\
HER2+/ER+ & $62(6.0)$ & $15(5.6)$ & \\
HER2+/ER- & $85(8.2)$ & $16(5.0)$ & \\
\hline
\end{tabular}

Table 3 Clinicopathological parameters of the NPI+ breast cancer biological classes in the Budapest series

\begin{tabular}{|c|c|c|c|c|c|c|c|c|}
\hline & $\begin{array}{l}\text { Luminal A } \\
(n=84) \\
n(\%)\end{array}$ & $\begin{array}{l}\text { Luminal N } \\
(n=32) \\
n(\%)\end{array}$ & $\begin{array}{l}\text { Luminal B } \\
(n=64) \\
n(\%)\end{array}$ & $\begin{array}{l}\text { Basal—p53 } \\
\text { altered }(n=18) \\
n(\%)\end{array}$ & $\begin{array}{l}\text { Basal—p53 } \\
\text { normal }(n=23) \\
n(\%)\end{array}$ & $\begin{array}{l}\mathrm{HER} 2+/ \\
\mathrm{ER}+ \\
(n=8) \\
n(\%)\end{array}$ & $\begin{array}{l}\mathrm{HER} 2+/ \\
\mathrm{ER}- \\
(n=3) \\
n(\%)\end{array}$ & $\begin{array}{l}\text { Cramer's V } \\
(p \text { value })\end{array}$ \\
\hline \multicolumn{9}{|l|}{ Size } \\
\hline$<15 \mathrm{~mm}$ & $24(30.0)$ & $10(30.6)$ & $19(30.6)$ & 7 (46.7) & $1(3.7)$ & $2(13.3)$ & $3(18.8)$ & $0.235(0.034)$ \\
\hline$\geq 15 \mathrm{~mm}$ & $56(70.0)$ & $21(69.4)$ & $43(69.4)$ & $8(53.3)$ & $26(96.3)$ & 13 (86.7) & $13(81.3)$ & \\
\hline \multicolumn{9}{|l|}{ Grade } \\
\hline 1 & $44(55.0)$ & $22(71.0)$ & $26(42.6)$ & $1(6.7)$ & $5(18.5)$ & $3(20.0)$ & 0 & $0.378(<0.001)$ \\
\hline 2 & $20(25.0)$ & $6(19.4)$ & $23(37.7)$ & $3(20.0)$ & $5(18.5)$ & $8(53.3)$ & $5(31.3)$ & \\
\hline 3 & $16(20.0)$ & $3(9.7)$ & $12(19.7)$ & $11(73.3)$ & $17(63.0)$ & $4(26.7)$ & $11(68.8)$ & \\
\hline \multicolumn{9}{|l|}{ LN stage } \\
\hline 1 & $34(61.8)$ & $8(42.1)$ & $21(46.7)$ & $4(33.3)$ & $12(52.2)$ & $4(26.7)$ & $4(36.4)$ & $0.211(0.188)$ \\
\hline 2 & $12(21.8)$ & 7 (36.8) & $17(37.8)$ & $2(16.7)$ & $5(21.7)$ & $6(40.0)$ & $4(36.4)$ & \\
\hline 3 & $9(16.4)$ & $4(21.1)$ & 7 (15.6) & $6(50.0)$ & $6(26.1)$ & $5(33.3)$ & $3(27.3)$ & \\
\hline \multicolumn{9}{|l|}{ NPI } \\
\hline Excellent & 13 (23.6) & $4(21.1)$ & $8(17.8)$ & 0 & $1(4.3)$ & $1(6.7)$ & 0 & $0.239(0.010)$ \\
\hline Good & 13 (23.6) & $6(31.6)$ & $8(17.8)$ & 0 & $3(13.0)$ & $1(6.7)$ & 0 & \\
\hline $\begin{array}{l}\text { Moderate } \\
1\end{array}$ & $16(29.1)$ & $5(26.3)$ & $11(24.4)$ & $2(18.2)$ & $5(21.7)$ & $4(26.7)$ & $1(9.1)$ & \\
\hline $\begin{array}{l}\text { Moderate } \\
2\end{array}$ & $6(10.9)$ & $1(5.3)$ & 7 (15.6) & $6(54.5)$ & $5(21.7)$ & $6(40.0)$ & $6(54.5)$ & \\
\hline Poor & $4(7.3)$ & $1(5.3)$ & 7 (15.6) & $2(18.2)$ & $4(17.4)$ & 0 & $2(18.2)$ & \\
\hline Very poor & $3(5.5)$ & $2(10.5)$ & $4(8.9)$ & $1(9.1)$ & $5(21.7)$ & $3(20.0)$ & $2(18.2)$ & \\
\hline
\end{tabular}


stage, tubule formation, nuclear pleomorphism and mitotic counts. These were identified as the most significant variables in the Nottingham series impacting on survival, according to their Beta value in Cox regression indicating the magnitude of the influence of the hazard. The Nottingham series was split into the NPI+ biological classes, and Cox regression analyses were performed independently for each class to identify the most significant clinicopathological prognostic factors and their beta value in the context of the individual classes. NPI+ Prognostic Groups for the Budapest series were assigned using the categorical cut-points previously derived from the Nottingham series in each of the NPI+ biological classes [8]. For this purpose, the original pathology assessments on full-face sections for the histopathologic parameters were utilised.

\section{Statistical analysis}

The association between BC classes and both histopathological and clinical characteristics was assessed using Cramer's V [20] to produce $p$ values. MFS differences between NPI+ biological classes and NPI+ Groups were determined using Kaplan-Meier curves using Log Rank. A $p<0.01$ was considered significant with Bonferroni adjustment for multiple testing.

\section{Results}

\section{$\mathrm{NPI}+$ in the Nottingham and Budapest series}

There were significant differences in the distribution of grade and stage (both $p<0.001$ ) of the breast tumours between the Nottingham and Budapest series with a larger proportion of the Nottingham series of a higher grade and lower stage (Table 1). The median follow-up for the Nottingham series was 9.9 years and the Budapest series was 8.1 years. A total of $363(33.9 \%)$ and $49(21.2 \%)$ patients developed distant metastases during the follow-up period in the Nottingham and Budapest series, respectively. There was, however, no difference in the MFS between the two series ( $p=0.236$, Supplementary Fig. 1$)$. The classic NPI significantly predicted MFS in both the Nottingham (Supplementary Fig. 1B, $p<0.001$ ) and Budapest (Supplementary Fig. $1 \mathrm{C}, p<0.001)$ series.

There was either very good (ER, PgR, CK7/8, EGFR, p53 and MUC1) or good (CK5/6 and HER4) concordance between the expression for the majority of markers across the two stained TMA cores whereas HER3 showed only moderate concordance (Supplementary Table 1). NPI+ biological class was determined in the Budapest series using the immunohistochemical data for the $10 \mathrm{NPI}+$ biomarkers. There was a difference in the distribution between each of the seven NPI+ biological classes (luminal A, luminal N, luminal B, basal p53 altered, basal p53 normal, HER2+/ER+ and HER2+/ER-) in Budapest series compared with the Nottingham series $(p<0.001$, Table 2). This was mainly due to the higher proportion of luminal B tumours in the Budapest series. A total of 5 cases $(2.0 \%)$ were not assigned to any class. There were significant associations between the clinicopathological parameters of the Budapest series and the NPI+ biological classes (Table 3). When comparing the MFS between the Nottingham and Budapest series, there were no significant differences in any of the luminal or basal NPI+ biological classes (Supplementary Fig. 2).

Bespoke NPI+ formulae, based on nodal number, tumour size, stage, and mitosis, for each of the seven NPI+ biological classes Rakha et al. [8] were applied to produce an NPI+ score, and then patients were further stratified into NPI+ Groups using the categorical cutpoints derived from the Nottingham series. The NPI+ score for the Budapest and Nottingham series was not significantly different from each other (mean $=2.71$ vs. $2.10, p=0.179)$.

Table 4 Distribution of the NPI+ Groups in the Budapest and Nottingham series

\begin{tabular}{|c|c|c|c|}
\hline NPI+ Group & $\begin{array}{l}\text { Budapest } \\
(n=178) \\
n(\%)\end{array}$ & $\begin{array}{l}\text { Nottingham } \\
(n=828) \\
n(\%)\end{array}$ & $p$ value \\
\hline \multicolumn{4}{|l|}{ Luminal A } \\
\hline Low risk & $23(12.9)$ & 148 (17.9) & \multirow[t]{3}{*}{$<0.001$} \\
\hline Moderate risk & $24(13.5)$ & $83(10.0)$ & \\
\hline High risk & $8(4.5)$ & $25(3.0)$ & \\
\hline \multicolumn{4}{|l|}{ Luminal $\mathrm{N}$} \\
\hline Low risk & $18(10.1)$ & $133(16.1)$ & \\
\hline High risk & $1(0.6)$ & $17(2.1)$ & \\
\hline \multicolumn{4}{|l|}{ Luminal B } \\
\hline Low risk & $41(23.0)$ & $77(9.3)$ & \\
\hline High risk & $2(1.1)$ & $58(7.0)$ & \\
\hline \multicolumn{4}{|c|}{ Basal-p53 altered } \\
\hline Low risk & $7(3.9)$ & $86(10.4)$ & \\
\hline High risk & $4(2.2)$ & $10(1.2)$ & \\
\hline \multicolumn{4}{|c|}{ Basal-p53 normal } \\
\hline Low risk & $24(13.5)$ & $44(5.4)$ & \\
\hline High risk & 0 & $28(3.4)$ & \\
\hline \multicolumn{4}{|l|}{ HER2 +/ER + } \\
\hline Low risk & $4(2.2)$ & $31(3.7)$ & \\
\hline High risk & $11(6.2)$ & $25(3.0)$ & \\
\hline \multicolumn{4}{|l|}{ HER2+/ER - } \\
\hline Low risk & $11(6.2)$ & $55(6.6)$ & \\
\hline High risk & 0 & $8(1.0)$ & \\
\hline
\end{tabular}


Although there was a significant difference in the distribution of the NPI+ Groups between the Nottingham and Budapest series (Table 4, $p<0.001$ ), a similar number of NPI+ Groups were evident in each of the Biological classes in both series Rakha et al. [8]. However, some of the poor prognostic groups were under-represented in the Budapest series due to the relatively lower frequency of highly proliferative tumours in the series.

\section{NPI+ and risk of distant metastases}

In the Nottingham Series, the biological classes were significantly associated with patient MFS where the luminal A (HR 1.57, $p=0.006$ ) and luminal N (HR 1.49, $p=0.024$ ) classes had a significantly better survival than the luminal B class (Figs. 1, 2). Luminal A tumours also had a significantly better MFS than basal p53 altered (HR 1.49, $p=0.043$ ), basal p53 normal (HR 1.80, $p=0.003$ ), HER2+/ER+ (HR 2.69, $p<0.001)$ and HER2+/ER(HR 2.47, $p<0.001$ ) tumours. Similarly, luminal N tumours had a significantly longer MFS than basal p53 normal (HR 1.66, $p=0.014)$, HER2+/ER+ (HR 2.47, $p<0.001$ ) and HER2+/ER- (HR 2.19, $p<0.001$ ) tumours but not the basal-p53 altered class $(p=0.135)$. There was no significant difference in MFS between basal p53 altered and basal p53 normal with the HER2+/ER+ or HER2+/ER - classes.

The NPI+ was used to determine the effect on MFS in the different molecular classes where NPI+ outcome prediction was compared with that achieved by the traditional
Fig. 2 Patient stratification for MFS with the classic NPI (left) compared with NPI+ (right) in each of the biological classes in the Nottingham series. a-b luminal A, c-d luminal N, e-f luminal B, gh basal p53 altered, i-j Basal p53 normal, k-L HER2+/ER+, mn HER2+/ER-. EPG excellent prognostic group, $G P G$ good prognostic group, $M P G$ moderate prognostic group, $P P G$ poor prognostic group, $V P G$ very poor prognostic group

NPI in each of the biological classes (Fig. 2a-n). In addition to improved outcome prediction using NPI+ compared with the traditional NPI in each class, NPI+ provided more clinically relevant stratification with splitting of each class into two or three prognostic groups compared with the six classes of NPI.

When comparing the patient outcome in each of the NPI+ prognostic groups between the Nottingham and Budapest Series, there were no significant differences in MFS in the majority of them (Supplementary Fig. 2). Certain high-risk NPI+ Groups (luminal N; luminal B; basal p53 normal and HER2+/ER) could not be validated due to being under-represented in the Budapest series.

NPI+ Groups were additionally able to predict a higher risk of metastases to certain distant sites, summarised in Table 5. Bone metastases were significantly more likely to occur in the poor prognostic group of the luminal $\mathrm{B}$, basal p53 altered, HER2+/ER + and HER2+/ER - classes and a lower risk in the good prognostic group of luminal A, basal p53 normal, HER2+/ER + and HER2+/ER - classes. Lung metastases were associated with the higher risk groups of Basal, HER2+ and luminal $\mathrm{N}$ tumours. Metastases to the brain were associated with HER2+ tumours only,

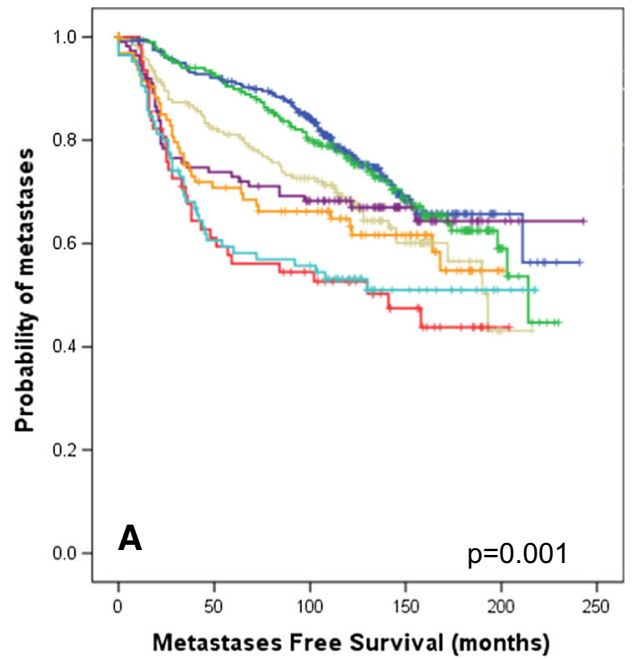

\begin{tabular}{|c|c|}
\hline $\begin{array}{l}\text { Luminal } A n=288 \\
\text { Luminal } N n=205 \\
\text { Luminal } B n=186 \\
\text { Basal p53 altered } n=113 \\
\text { Basal p53 normal } n=96 \\
\text { HER2+/ER+ } n=62 \\
\text { HER2+/ER- } n=85\end{array}$ & $\begin{array}{l}\mathrm{HR}=1.14(0.82-1.59) p=0.446 \\
\mathrm{HR}=1.52(1.09-2.13) \mathrm{p}=0.014 \\
\mathrm{HR}=1.45(0.98-2.16) \mathrm{p}=0.064 \\
\mathrm{HR}=1.75(1.17-2.61) \mathrm{p}=0.006 \\
\mathrm{HR}=2.56(1.69-3.88) \mathrm{p}<0.001 \\
\mathrm{HR}=2.001\end{array}$ \\
\hline
\end{tabular}

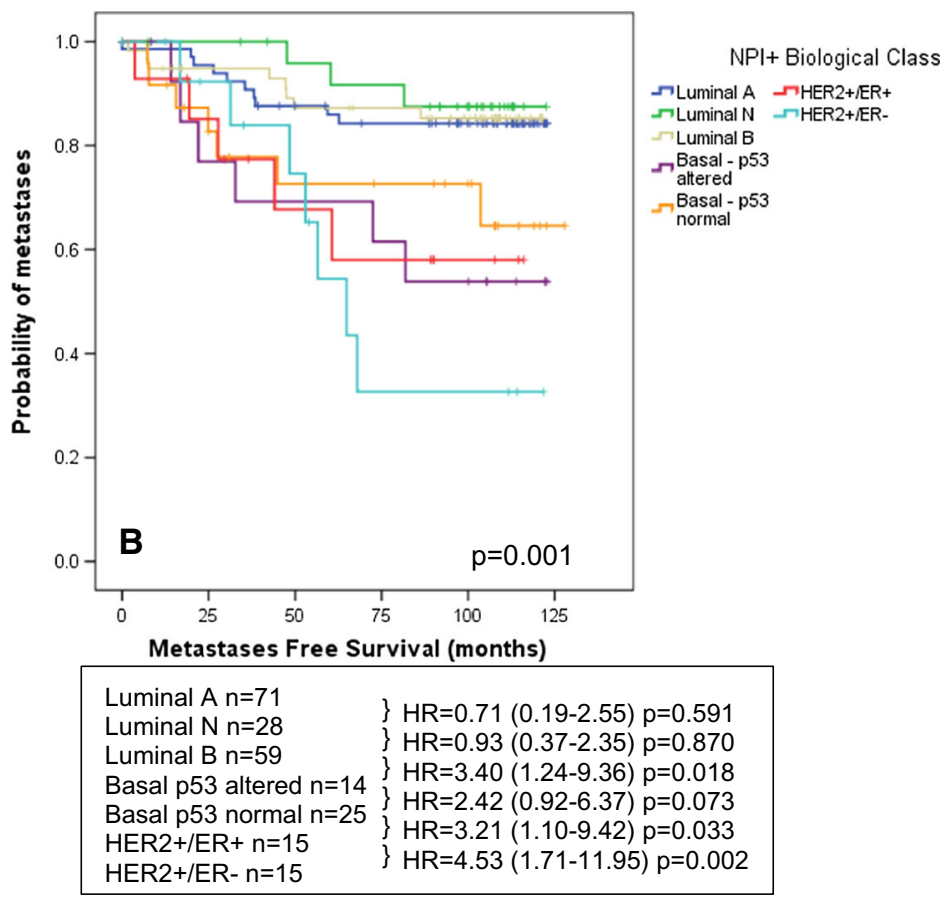

Fig. 1 MFS with respect to NPI+ biological classes. a Nottingham and b Budapest series 

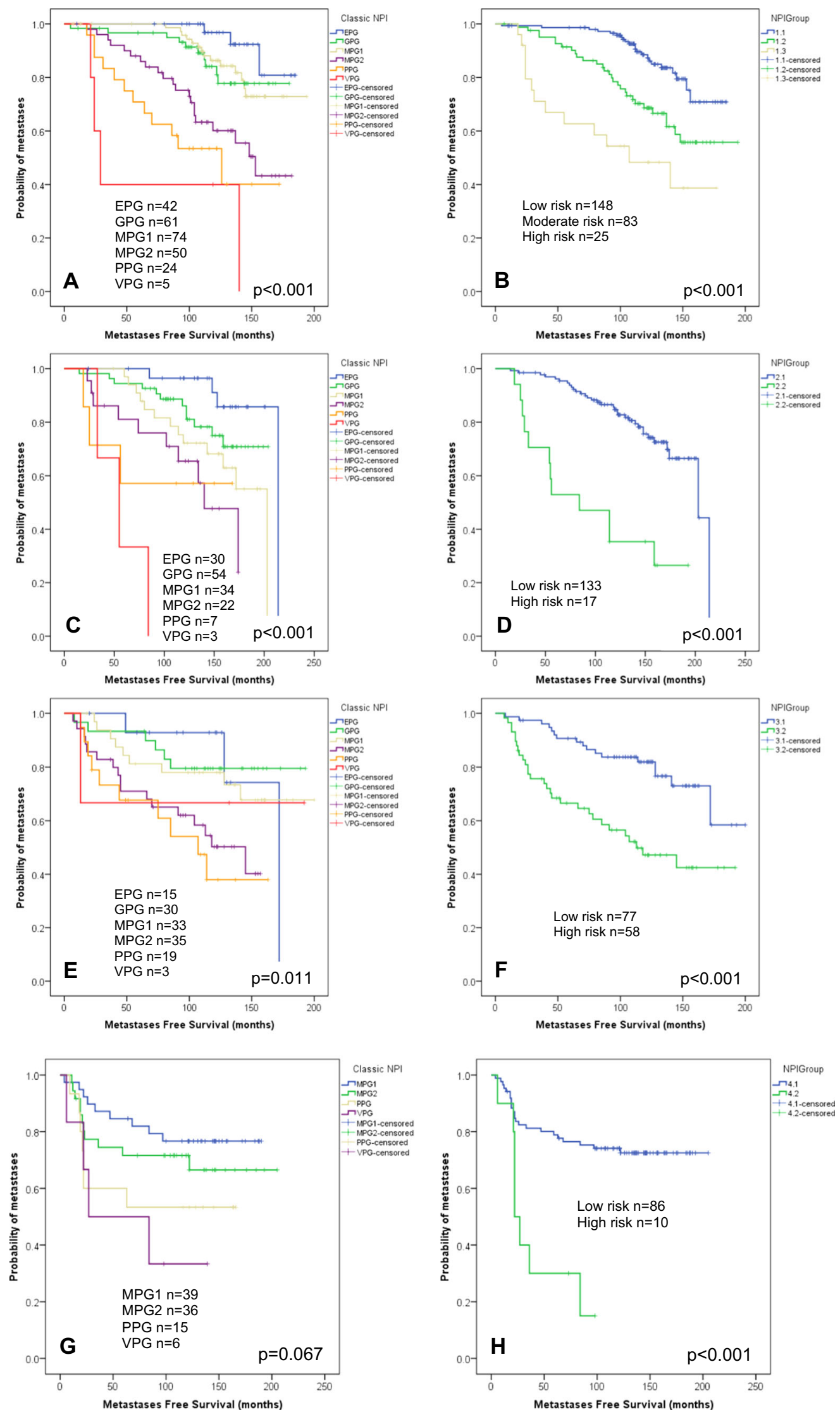

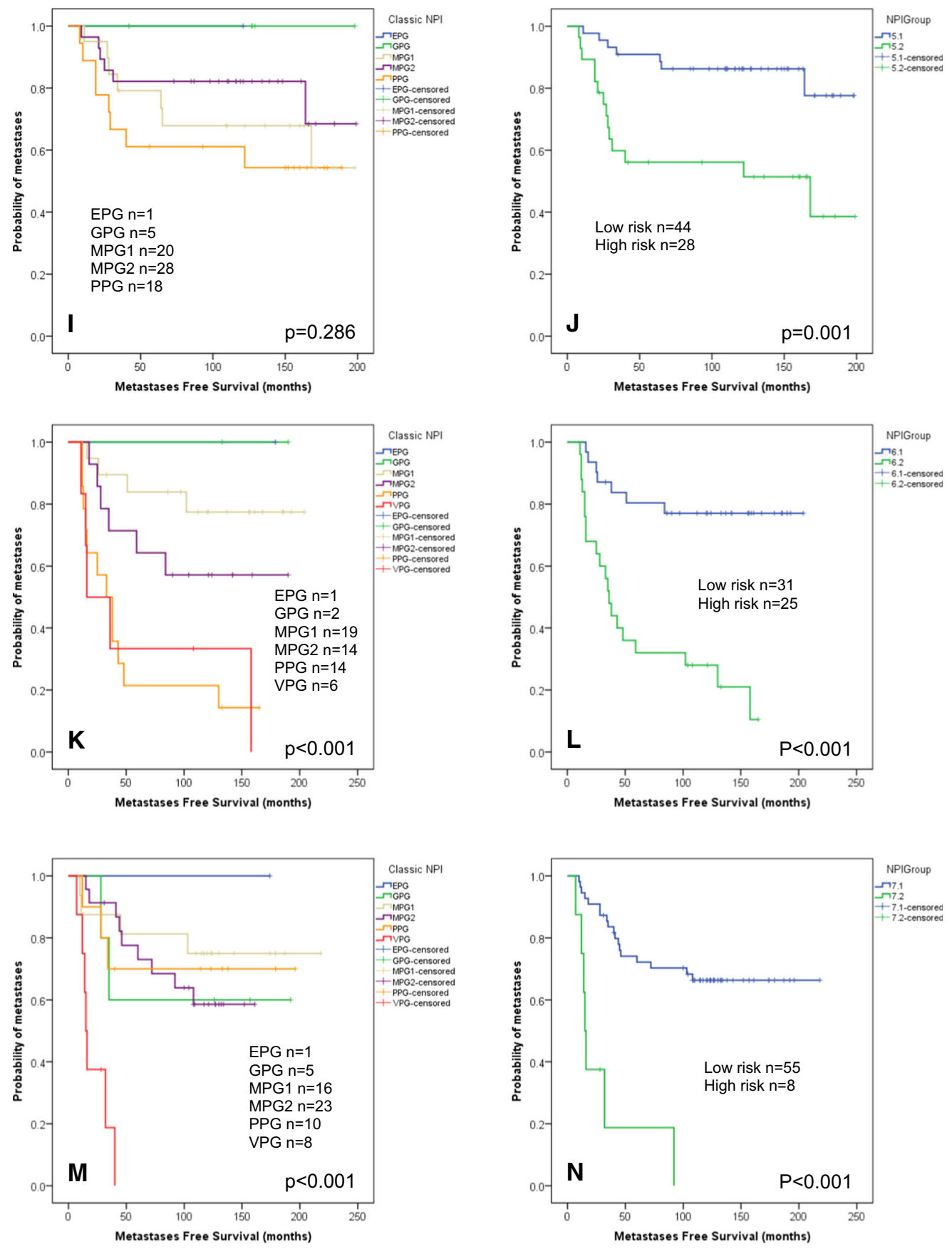

Fig. 2 continued

irrespective of ER status, with poor prognostic tumours having a higher incidence of brain metastases compared with good prognostic tumours. A higher incidence of liver metastases were associated with moderate and poor prognostic luminal A tumours and luminal B poor prognostic tumours compared with luminal A good prognostic tumours which had a significantly lower incidence $(p<0.001)$. Additionally, basal, both p53 altered and normal tumours, in NPI+ high-risk groups had a significantly higher incidence of liver metastases than basal p53

normal tumours in the low risk group. There was no association between NPI+ and number of metastatic sites (data not shown).

\section{Discussion}

Contemporary treatment of $\mathrm{BC}$ requires the integration of clinicopathological and biological information to ensure effective stratification of patients with regard to their 
Table 5 NPI+ prognostic groups and site of distant metastases

\begin{tabular}{|c|c|c|c|c|c|c|c|c|}
\hline & \multicolumn{8}{|c|}{ Site of distant metastases } \\
\hline & \multicolumn{2}{|l|}{ Bone } & \multicolumn{2}{|l|}{ Liver } & \multicolumn{2}{|l|}{ Lung } & \multicolumn{2}{|l|}{ Brain } \\
\hline & $n(\%)$ & $p$ value & $n(\%)$ & $p$ value & $n(\%)$ & $p$ value & $n(\%)$ & $p$ value \\
\hline \multicolumn{9}{|l|}{ Luminal A } \\
\hline Low risk & $15(10.1)$ & $<0.001$ & $9(6.1)$ & $<0.001$ & $3(2.0)$ & 0.002 & $4(2.7)$ & $<0.001$ \\
\hline Moderate risk & $20(24.1)$ & & $17(20.5)$ & & $13(15.7)$ & & $4(4.8)$ & \\
\hline High risk & $10(40.0)$ & & $8(32.0)$ & & $3(12.0)$ & & $4(16.0)$ & \\
\hline \multicolumn{9}{|l|}{ Luminal N } \\
\hline Low risk & $21(15.8)$ & & $12(9.0)$ & & $13(9.8)$ & & $3(2.3)$ & \\
\hline High risk & $8(47.1)$ & & $3(17.6)$ & & $3(17.6)$ & & $1(5.9)$ & \\
\hline \multicolumn{9}{|l|}{ Luminal B } \\
\hline Low risk & $11(14.3)$ & & $7(9.1)$ & & $2(2.6)$ & & $2(2.6)$ & \\
\hline High risk & $25(43.1)$ & & $13(22.4)$ & & $6(10.3)$ & & $2(3.4)$ & \\
\hline \multicolumn{9}{|c|}{ Basal p53 altered } \\
\hline Low risk & $11(12.8)$ & & $7(8.1)$ & & $8(9.3)$ & & $9(10.5)$ & \\
\hline High risk & $5(50.0)$ & & $3(30.0)$ & & $2(20.0)$ & & $1(10.0)$ & \\
\hline \multicolumn{9}{|l|}{ Basal p53 normal } \\
\hline Low risk & $2(4.5)$ & & 0 & & $3(6.8)$ & & $1(2.3)$ & \\
\hline High risk & $24(14.3)$ & & $6(21.4)$ & & $3(10.7)$ & & $3(10.7)$ & \\
\hline \multicolumn{9}{|l|}{ HER2+/ER + } \\
\hline Low risk & $4(12.9)$ & & 7 (22.6) & & $2(6.5)$ & & 0 & \\
\hline High risk & $12(48.0)$ & & $11(44.0)$ & & $5(20.0)$ & & $5(20.0)$ & \\
\hline \multicolumn{9}{|l|}{ HER2+/ER- } \\
\hline Low risk & $9(16.4)$ & & $11(20.0)$ & & $4(7.3)$ & & $2(3.6)$ & \\
\hline High risk & $3(37.5)$ & & $3(37.5)$ & & $3(37.5)$ & & $3(37.5)$ & \\
\hline
\end{tabular}

expected outcome and response to the ever increasing treatment options. Molecular gene assays, such as Oncotype $\mathrm{DX}^{\circledR}$ [21] and MammaPrint ${ }^{\circledR}$ [22], are limited in their clinical utility for the management of $\mathrm{BC}$ due to factors including reproducibility, validation, cost and targeting only certain BC patients.

We have developed the NPI+ based on the integration of clinical, histopathological and biological data; we determined using routine clinical methodology, which is envisaged to assist clinicians in offering a more personalised adjuvant treatment plan in all early-stage BC patients. Whilst the clinical utility of NPI+ in predicting patient survival has previously been determined [8], we had previously not explored the capability of NPI+ with respect to prediction of risk of metastases. We therefore sought to confirm the prognostic capabilities of NPI+ in predicting risk of metastases in two independent European series of BC (Nottingham and Budapest).

NPI+ uses well-established powerful clinicopathologic variables to stratify each of the biological classes into clinically distinct subgroups using bespoke NPI-like formulae. In the Nottingham series, each biological class was previously stratified into at least two prognostic groups which were predictive of breast cancer-specific survival [8]. Using these prognostic groups, we further show that the NPI+ can predict either a low or high risk of developing metastases after receiving standard adjuvant therapy. The combination of biological class and clinicopathological parameters used in the NPI+ provided enhanced prognostic information for patients with $\mathrm{BC}$ into more clinically relevant subgroups compared with the classic NPI. Those patients with an adverse risk of tumour relapse are clearly identified as candidates for additional or alternative forms of therapy as the conventional $\mathrm{BC}$ management at the time of diagnosis has failed to minimise metastatic disease. We also confirm that biological subtypes of $\mathrm{BC}$ are associated with particular metastatic behaviour where bone metastases were common across all biological subtypes, whereas brain metastases were specifically associated with HER2 + tumours [23].

We further sought to validate and confirm the prognostic capabilities of NPI+ in an independent series of BC from a separate centre (Budapest, Hungary). Although there was some difference in the overall distribution of size, stage and grade of tumours between the Nottingham and Hungary series, the number of NPI+ biological classes was 
similar. This is consistent with the proportion of cancer subtypes reported in our previous validation [13] and other studies [9, 11, 22, 24-31], and further provides evidence that the classification of $\mathrm{BC}$ into seven biological classes can be achieved using a discrete panel of 10 proteins assessed by immunohistochemistry.

In the Budapest series, the NPI+ Prognostic Groups showed comparable MFS when compared with the Nottingham series in NPI+ biological classes: luminal A and basal p53 altered. The NPI+ Prognostic Groups with a low risk of metastases were similarly validated in the NPI+ biological classes: luminal N, luminal B, basal p53 normal along with the high risk NPI+ Prognostic Group in the HER2+/ER + class. However, due to very small numbers of patients assigned in the Budapest series in the remaining NPI+ Prognostic Groups of biological classes, Luminal N, Luminal B, Basal p53 normal and HER2+/ER - could not be validated.

In conclusion, the NPI+ can stratify patients with BC of any biological class type into a category of expected low or high risk of developing metastases following conventional therapy and confirmed in an independent series of primary BC. It is envisaged that an NPI+ risk stratification index score could be developed to replace assignment of patients into either a good or adverse outcome group.

We confirm that the NPI+ is a reproducible tool that provides improved individualised clinical decision making for breast cancer by refinement of clinical prediction. Advantages in applying the NPI+ in clinical decision making for $\mathrm{BC}$ patients are improved prognostication and risk stratification, and the potential for health economic savings through appropriate targeted treatment. Additionally, NPI+ uses routine clinical samples and robust laboratory methods integrating easily into current international clinical practice. Further validation of the clinical validity of NPI+ using modern eta treatments in randomised clinical trial material is therefore warranted.

Acknowledgments We thank Chris Sheehan and Caroline Sykes. The study was funded by the Medical Research Council DPFS Scheme to establish a biomarker-based prognostic assay (NPI+) for breast cancer. AMS was supported by the János Bolyai Research Scholarship of the Hungarian Academy of Sciences. AMT acknowledges the grant MKOT 2014.

Funding The study was funded by the Medical Research Council DPFS Scheme.

Statement of author contributions ARG, DGP, GRB, JMG, EAR and IOE conceived the study; ARG, CCN, and DGP carried out experiments; ARG, DS, JS, MA, and DGP performed data analysis; JK, AMS, and AMT provided tissue microarrays together with clinicopathological and outcome data for Budapest cases. All authors were involved in data interpretation, writing the paper and had final approval of the submitted and published manuscript.
Compliance with ethical standards

Conflict of interest The authors have no conflicts of interest to disclose.

Open Access This article is distributed under the terms of the Creative Commons Attribution-NonCommercial 4.0 International License (http://creativecommons.org/licenses/by-nc/4.0/), which permits any noncommercial use, distribution, and reproduction in any medium, provided you give appropriate credit to the original author(s) and the source, provide a link to the Creative Commons license, and indicate if changes were made.

\section{References}

1. Weigelt B, Reis-Filho JS, Swanton C (2012) Genomic analyses to select patients for adjuvant chemotherapy: trials and tribulations. Ann Oncol 23(Suppl 10):x211-x218. doi:10.1093/annonc/mds323

2. Galea MH, Blamey RW, Elston CE, Ellis IO (1992) The Nottingham Prognostic Index in primary breast cancer. Breast Cancer Res Treat 22(3):207-219

3. Balslev I, Axelsson CK, Zedeler K, Rasmussen BB, Carstensen B, Mouridsen HT (1994) The Nottingham prognostic index applied to 9149 patients from the studies of the Danish Breast Cancer Cooperative Group (DBCG). Breast Cancer Res Treat 32(3):281-290

4. D'Eredita G, Giardina C, Martellotta M, Natale T, Ferrarese F (2001) Prognostic factors in breast cancer: the predictive value of the Nottingham prognostic index in patients with a long-term follow-up that were treated in a single institution. Eur $\mathrm{J}$ Cancer 37(5):591-596

5. Haybittle JL, Blamey RW, Elston CW, Johnson J, Doyle PJ, Campbell FC et al (1982) A prognostic index in primary breast cancer. Br J Cancer 45(3):361-366

6. Brown J, Jones M, Benson EA (1993) Comment on the Nottingham prognostic index. Breast Cancer Res Treat 25(3):283

7. Blamey RW, Ellis IO, Pinder SE, Lee AH, Macmillan RD, Morgan DA et al (2007) Survival of invasive breast cancer according to the Nottingham prognostic index in cases diagnosed in 1990-1999. Eur J Cancer 43(10):1548-1555

8. Rakha EA, Soria D, Green AR, Lemetre C, Powe DG, Nolan CC et al (2014) Nottingham prognostic index plus (NPI+): a modern clinical decision making tool in breast cancer. $\mathrm{Br} \mathrm{J}$ Cancer 110(7):1688-1697. doi:10.1038/bjc.2014.120

9. Abd El-Rehim DM, Ball G, Pinder SE, Rakha E, Paish C, Robertson JF et al (2005) High-throughput protein expression analysis using tissue microarray technology of a large wellcharacterised series identifies biologically distinct classes of breast cancer confirming recent cDNA expression analyses. Int $\mathbf{J}$ Cancer 116(3):340-350. doi:10.1002/ijc.21004

10. Soria D, Garibaldi JM, Ambrogi F, Green AR, Powe D, Rakha E et al (2010) A methodology to identify consensus classes from clustering algorithms applied to immunohistochemical data from breast cancer patients. Comput Biol Med 40(3):318-330. doi:10. 1016/j.compbiomed.2010.01.003

11. Green AR, Powe DG, Rakha EA, Soria D, Lemetre C, Nolan CC et al (2013) Identification of key clinical phenotypes of breast cancer using a reduced panel of protein biomarkers. Br J Cancer 109(7):1886-1894. doi:10.1038/bjc.2013.528

12. Soria D, Garibaldi JM, Green AR, Powe DG, Nolan CC, Lemetre C et al (2013) A quantifier-based fuzzy classification system for breast cancer patients. Artif Intell Med 58(3):175-184. doi:10. 1016/j.artmed.2013.04.006 
13. Green AR, Soria D, Stephen J, Powe DG, Nolan CC, Kunkler I et al (2016) Nottingham prognostic index plus: validation of a clinical decision making tool in breast cancer in an independent series. J Pathol: Clin Res 2(1):32-40

14. Kulka J, Szasz AM, Nemeth Z, Madaras L, Schaff Z, Molnar IA et al (2009) Expression of tight junction protein claudin-4 in basal-like breast carcinomas. Pathol Oncol Res 15(1):59-64. doi:10.1007/s12253-008-9089-x

15. McCarty KS Jr, Miller LS, Cox EB, Konrath J, McCarty KS Sr (1985) Estrogen receptor analyses. Correlation of biochemical and immunohistochemical methods using monoclonal antireceptor antibodies. Arch Pathol Lab Med 109(8):716-721

16. Goulding H, Pinder S, Cannon P et al (1995) A new method for the assessment of oestrogen receptor status on routine formalinfixed tissue samples. Hum Pathol 26:291-294

17. Wolff AC, Hammond ME, Schwartz JN, Hagerty KL, Allred DC, Cote RJ et al (2007) American Society of Clinical Oncology/ College of American Pathologists guideline recommendations for human epidermal growth factor receptor 2 testing in breast cancer. J Clin Oncol 25(1):118-145

18. Garcia-Caballero T, Grabau D, Green AR, Gregory J, Schad A, Kohlwes E et al (2010) Determination of HER2 amplification in primary breast cancer using dual-colour chromogenic in situ hybridization is comparable to fluorescence in situ hybridization: a European multicentre study involving 168 specimens. Histopathology 56(4):472-480. doi:10.1111/j.1365-2559.2010. 03503.x

19. McShane LM, Altman DG, Sauerbrei W, Taube SE, Gion M, Clark GM (2005) Reporting recommendations for tumor marker prognostic studies (REMARK). J Natl Cancer Inst 97(16):1180-1184. doi:10.1093/jnci/dji237

20. Friendly M (2000) Visualizing categorical data. SAS Institute, Cary

21. Paik S, Shak S, Tang G, Kim C, Baker J, Cronin M et al (2004) A multigene assay to predict recurrence of tamoxifen-treated, nodenegative breast cancer. N Engl J Med 351(27):2817-2826. doi:10. 1056/NEJMoa041588

22. van de Vijver MJ, He YD, van't Veer LJ, Dai H, Hart AA, Voskuil DW et al (2002) A gene-expression signature as a pre- dictor of survival in breast cancer. $\mathrm{N}$ Engl $\mathrm{J}$ Med 347(25):1999-2009. doi:10.1056/NEJMoa021967

23. Kennecke H, Yerushalmi R, Woods R, Cheang MC, Voduc D, Speers CH et al (2010) Metastatic behavior of breast cancer subtypes. J Clin Oncol 28(20):3271-3277. doi:10.1200/JCO. 2009.25.9820

24. Ambrogi F, Biganzoli E, Querzoli P, Ferretti S, Boracchi P, Alberti S et al (2006) Molecular subtyping of breast cancer from traditional tumor marker profiles using parallel clustering methods. Clin Cancer Res 12(3 Pt 1):781-790

25. Callagy G, Cattaneo E, Daigo Y, Happerfield L, Bobrow LG, Pharoah PD et al (2003) Molecular classification of breast carcinomas using tissue microarrays. Diagn Mol Pathol 12(1):27-34

26. Perou CM, Jeffrey SS, van de Rijn M, Rees CA, Eisen MB, Ross DT et al (1999) Distinctive gene expression patterns in human mammary epithelial cells and breast cancers. Proc Natl Acad Sci USA 96(16):9212-9217

27. Sorlie T, Perou CM, Tibshirani R, Aas T, Geisler S, Johnsen H et al (2001) Gene expression patterns of breast carcinomas distinguish tumor subclasses with clinical implications. Proc Natl Acad Sci USA 98(19):10869-10874

28. van 't Veer LJ, Dai H, van de Vijver MJ, He HD, Hart AA, Bernards R et al (2003) Expression profiling predicts outcome in breast cancer. Breast Cancer Res 5(1):57-58

29. Nielsen TO, Parker JS, Leung S, Voduc D, Ebbert M, Vickery T et al (2010) A comparison of PAM50 intrinsic subtyping with immunohistochemistry and clinical prognostic factors in tamoxifen-treated estrogen receptor-positive breast cancer. Clin Cancer Res 16(21):5222-5232. doi:10.1158/1078-0432.CCR-10-1282

30. Parker JS, Mullins M, Cheang MC, Leung S, Voduc D, Vickery T et al (2009) Supervised risk predictor of breast cancer based on intrinsic subtypes. J Clin Oncol 27(8):1160-1167

31. Darb-Esfahani S, Loibl S, Muller BM, Roller M, Denkert C, Komor $M$ et al (2009) Identification of biology-based breast cancer types with distinct predictive and prognostic features: role of steroid hormone and HER2 receptor expression in patients treated with neoadjuvant anthracycline/taxane-based chemotherapy. Breast Cancer Res 11(5):R69 